\title{
People With Parkinson's Disease and Freezing of Gait Show Abnormal Low Frequency Activity of Antagonistic Leg Muscles
}

\author{
Maria-Sophie Breu ${ }^{1,2 *}$, Marlieke Schneider ${ }^{1,2}$, Johannes Klemt ${ }^{1,2}$, Idil Cebi ${ }^{1,2}$, \\ Alireza Gharabaghi ${ }^{3}$ and Daniel Weiss ${ }^{1,2 *}$ \\ ${ }^{1}$ Centre of Neurology, Department of Neurodegenerative Diseases, University of Tübingen, Tübingen, Germany, ${ }^{2}$ Hertie \\ Institute for Clinical Brain Research, Tübingen, Germany, ${ }^{3}$ Centre for Neurosurgery, Institute for Neuromodulation \\ and Neurotechnology, University of Tübingen, Tübingen, Germany
}

\section{OPEN ACCESS}

Edited by:

Monika Pötter-Nerger, University of Hamburg, Germany

Reviewed by: Daniel Boari Coelho, Federal University of $A B C$, Brazi

Chiara Palmisano,

Julius Maximilian University of Würzburg, Germany

*Correspondence:

Maria-Sophie Breu

maria-sophie.breu@

med.uni-tuebingen.de Daniel Weiss

daniel.weiss@uni-tuebingen.de

Specialty section: This article was submitted to

Motor Neuroscience,

a section of the journal

Frontiers in Human Neuroscience

Received: 29 June 2021 Accepted: 03 December 2021

Published: 26 January 2022

Citation:

Breu M-S, Schneider M, Klemt J, Cebi I, Gharabaghi A and Weiss D

(2022) People With Parkinson's Disease and Freezing of Gait Show Abnormal Low Frequency Activity

of Antagonistic Leg Muscles. Front. Hum. Neurosci. 15:733067. doi: 10.3389/fnhum.2021.733067
Objective: Freezing of gait is detrimental to patients with idiopathic Parkinson's disease (PD). Its pathophysiology represents a multilevel failure of motor processing in the cortical, subcortical, and brainstem circuits, ultimately resulting in ineffective motor output of the spinal pattern generator. Electrophysiological studies pointed to abnormalities of oscillatory activity in freezers that covered a broad frequency range including the theta, alpha, and beta bands. We explored muscular frequency domain activity with respect to freezing, and used deep brain stimulation to modulate these rhythms thereby evaluating the supraspinal contributions to spinal motor neuron activity.

Methods: We analyzed 9 PD freezers and 16 healthy controls $(\mathrm{HC})$. We studied the patients after overnight withdrawal of dopaminergic medication with stimulation off, stimulation of the subthalamic nucleus (STN-DBS only) or the substantia nigra pars reticulate $\left(\mathrm{SNr}-\mathrm{DBS}_{\mathrm{on}} \mathrm{y}\right)$, respectively. Patients performed a walking paradigm passing a narrow obstacle. We analyzed the frequency-domain spectra of the tibialis anterior (TA) and gastrocnemius (GA) muscles in 'regular gait' and during the 'freezing' episodes.

Results: In stimulation off, PD freezers showed increased muscle activity of the alpha and low-beta band compared to $\mathrm{HC}$ in both TA and GA. This activity increase was present during straight walking and during the freezes to similar extent. STN- but not SNr-DBS decreased this activity and paralleled the clinical improvement of freezing.

Conclusion: We found increased muscle activation of the alpha and lower beta band in PD freezers compared to HC, and this was attenuated with STN-DBS. Future studies may use combined recordings of local field potentials, electroencephalography (EEG), and electromyography (EMG) to interrogate the supraspinal circuit mechanisms of the pathological activation pattern of the spinal pattern generator.

\footnotetext{
Keywords: Parkinson's disease, EMG, freezing of gait (FOG), low frequency activation, DBS (deep brain stimulation)
}

Abbreviations: DBS, deep brain stimulation; PD, Parkinson's disease; HC, healthy controls; STN, subthalamic nucleus; SNr, substantia nigra pars reticulate; MLR, mesencephalic locomotor region; PMRF, ponto-medullary reticular formation; EEG electroencephalography; EMG, emelctromyography; ULF, upper limb freezing; TA, tibialis anterior; GA, gastrocnemius; PPN, pedunculo-pontine nucleus; TO, toe-off; HS, heel-strike; MS, midswing; FFT, fast Fourier transform. 


\section{INTRODUCTION}

Freezing of gait (FoG) in Parkinson's disease (PD) represents the defective spinal motor output depending on the supraspinal cortical, subcortical, and brainstem contributions (Lewis and Shine, 2016; Snijders et al., 2016; Weiss et al., 2020). As such the motor, cognitive, and emotional systems (Shine et al., 2013; Ehgoetz Martens et al., 2018) modulate the effective spinal motor output according to the environmental and internal requirements (Drew et al., 2004; Snijders et al., 2016). In particular, the spinal pattern generator is modulated by the descending drives of the pyramidal tract and the nigro-ponto-reticulospinal pathway (Nutt et al., 2011; Snijders et al., 2016).

The rhythmic alternation of stepping during regular gait is generated in the spinal cord in humans (Guertin, 2009). Historically, early experimental studies in decerebrate cats suggested that the spinal pattern generator generates rhythmic locomotion, even in the absence of supraspinal input. The cats were able to walk, trot and gallop when put on a treadmill, but the gait was mechanical and inflexible (Mori, 1987; Snijders et al., 2016). Further, experimental models found that the descending drives to spinal motor neurons stem from nuclei of the mesencephalic locomotor region (MLR) including the pedunculopontine and cuneiform nucleus and the reticulospinal projections (Jordan et al., 2008; Takakusaki, 2013; Snijders et al., 2016). Previous experimental and clinical research supported that human gait can be modulated both on the level of the substatia nigra, pars resticulate ( $\mathrm{SNr}$ ) based on the monosynaptic GABAergic projection from the $\mathrm{SNr}$ (Weiss et al., 2013; Scholten et al., 2017; Heilbronn et al., 2019; Valldeoriola et al., 2019) to the pedunculo-pontine nucleus (PPN) (Ferraye et al., 2010; GarciaRill et al., 2019). Experimental research suggested that both dopaminergic depletion and pharmacological des-inhibition increased GABAergic $\mathrm{SNr}$ activity resulting in a pro-akinetic net effect (Burbaud et al., 1998; Breit et al., 2006). Instead, pharmacological or electrical $\mathrm{SNr}$ inhibition led to prokinetic effects including those on gait (Wichmann et al., 2001; LafreniereRoula et al., 2010; Sutton et al., 2013; Milosevic et al., 2018). Experimental research established a reciprocal link between $\mathrm{SNr}$ and PPN, showing the reciprocal regulation of single cell activity of the two nuclei (Breit et al., 2001, 2006). In human PD, nigral stimulation modulated clinical and kinematic gait measures (Scholten et al., 2017; Heilbronn et al., 2019) and FoG. Yet, it has to be kept in mind that these conclusions stem from piloting observations and have to be confirmed in larger clinical trials (Snijders et al., 2016; Garcia-Rill et al., 2019; Weiss et al., 2020).

Less so the model work but more the clinical and neurophysiological human PD gait research pointed to the fact that the subthalamo-cortical circuits may be more meaningful in PD gait than was anticipated in experimental work. In particular, patients with L-Dopa sensitive FoG may show considerable therapeutic benefit from subthalamic nucleus deep brain stimulation (STN-DBS) (Schlenstedt et al., 2017; Barbe et al., 2020; Cebi et al., 2020). The STN holds both inhibitory indirect and hyperdirect projections to the primary motor cortex (Delwaide et al., 2000; Gradinaru et al., 2009), and high-frequency stimulation of the STN modulated activity and excitability of the primary motor cortex (Kuriakose et al., 2010; Udupa et al., 2016) as well as of the associated premotor and prefrontal cortical areas (de Hemptinne et al., 2015; Weiss et al., 2015). However, stimulation of the STN does not exclusively act on the subthalamo-cortical circuit, but also entrains brainstem connections including in PD gait (Pötter et al., 2008). The subthalamic contributions to PD gait and freezing phenomena have more recently been highlighted with neurophysiological techniques studying oscillatory activity of STN local field potentials and cortical activity. Traditionally, enhanced broad alpha and beta band activity $(8-35 \mathrm{~Hz})$ from STN-LFPs correlated with bradykinesia and rigidity (Brown, 2003; Kühn et al., 2006, 2009) and were suppressed with effective STN-DBS therapy (Kühn et al., 2008; Eusebio et al., 2012). More recent studies linked oscillatory activity with freezing phenomena. As such, PD freezers showed elevated activation around $18 \mathrm{~Hz}$ at movement initiation (Storzer et al., 2017) compared to non-freezers. Additionally, pathologically prolonged broad band beta burst duration (Tinkhauser et al., 2017) was associated to freezing, since beta burst duration (13-30 Hz band) was more prolonged in PD freezers compared to non-freezers during regular gait and more pronounced during the freezing episodes (Anidi et al., 2018).

In addition to STN, the cortex is involved in freezing phenomena as indicated from oscillatory activity and cortical stimulation studies, as reviewed elsewhere (Weiss et al., 2019). Briefly, upper limb freezing (ULF) showed enhanced activity around and below $10 \mathrm{~Hz}$ during a freeze in the alpha band (Scholten et al., 2016a). Moreover, cortical abnormalities of both cortico-cortical synchronization (Scholten et al., 2016b) and beta band decoupling abnormalities prior to a freeze indicated premonitory cortical susceptibility to freezing (Scholten et al., 2020). There were similar findings in FoG, when corticosubthalamic decoupling in the low frequency band (4$13 \mathrm{~Hz}$ ) became evident not only during freezing episodes, but also preceded a freeze (Pozzi et al., 2019). Finally, similar abnormalities were found in the PPN when freezing episodes showed attenuated alpha activity (Thevathasan et al., 2012), and electromyography (EMG) studies showed enhanced activity below $10 \mathrm{~Hz}$ in the PD off state in general (Salenius et al., 2002; Weiss et al., 2012). More specific, activity around and below $10 \mathrm{~Hz}$ was found in freezers and during ULF, and was suppressed by STN-DBS (Scholten et al., 2016a).

Little is known about the pathological changes in the frequency domain in muscular activity in PD patients when exhibiting FoG. Based on the current literature, we explored muscular activity in broad frequency range from 1 to $45 \mathrm{~Hz}$ comprising the above mentioned frequency bands, and compared to healthy controls (HC). Derived from these findings, we further explored if activation abnormalities of the alpha and beta frequency were related to freezing episodes. Then, we used DBS therapy to differentially modulate the basal ganglia contributions to the spinal motor neurons, applying both STN and SNr stimulation, respectively. We posited that - if the supraspinal contribution of each nucleus was relevant to spinal motor activity and FoG - neuromodulation of either target should modulate both the clinical expression of freezing 
and the activity of the antagonistic tibialis anterior (TA) and gastrocnemius (GA) muscles.

\section{MATERIALS AND METHODS}

\section{Subject Characteristics}

We included 16 patients with idiopathic PD and DBS and 16 ageand gender-matched HC. From these, we selected 11 PD patients with clinically confirmed FoG episodes (Snijders et al., 2012). We excluded two further PD patients from analysis, one owing to technical problems during the recording and another owing to the inability to walk during the experimental session. Finally, we analyzed data from $9 \mathrm{PD}$ freezers ( 3 female, age $66.4 \pm 7.2$ years) and $16 \mathrm{HC}$ ( 6 female, age: $58.5 \pm 4.6$ years). Detailed patient characteristics are given in Table $\mathbf{1}$.

Inclusion criteria were idiopathic PD with akinesia-rigidity type and time since DBS implantation more than 3 months. Exclusion criteria were Mini Mental Status Examination $<22$, Beck's Depression Inventory $>13$, and other neurological or neuromuscular disease except PD. The local Ethics committee of the University of Tübingen approved the study (application no. $732 / 2012 \mathrm{BO} 2$ ) and all subjects provided written consent to participate in the study.

\section{Experimental Setup Paradigm}

During the experimental session, patients walked repeatedly on a straight over ground walkway of $9 \mathrm{~m}$ forth and back. We installed two obstacles at $1 / 3$ and $2 / 3$ along the hallway to narrow the pathway in order to provoke FoG episodes (Rahman et al., 2008). The patients self-initiated walking and walked in their self-selected, comfortable pace for about $3 \mathrm{~min}$, or at least as long as possible, the minimum walking period analyzed in a single patient was 70 s. All patients walked freely except patient PD2, who wished to use a walking aid uniformly in all therapy conditions. Patients were studied in three stimulation conditions after overnight withdrawal of dopaminergic medication (MedOff). Therefore, we recorded patients in stimulation off ('StimOff'), stimulation of only STN: STN ${ }_{\text {only }}$ (briefly 'STN'), and stimulation of only SNr: $\mathrm{SNr}_{\text {only }}$ (briefly ' $\mathrm{SNr}$ '), and the three conditions were delivered in randomized order. Electrode localization of the active contacts was located in the STN (electrode model 3389, Medtronic, Minneapolis, MN, United States), additionally in 8 out of 9 patients the lowermost electrode contact reached the $\mathrm{SNr}$ area \{at least $-5 \mathrm{~mm}$ below the midcommisural point [MCP, mean coordinates of the cohort: left SNr: $-11.0( \pm 0.6),-3.6( \pm 0.4),-$ $7.1( \pm 0.5)$, right SNr: $10.3( \pm 0.5),-3.6( \pm 0.4),-6.2( \pm 0.3)$; left STN: $-13.0( \pm 0.6),-1.4( \pm 0.4),-3.3( \pm 0.4)$; right STN: $12.1( \pm 0.4),-1.2( \pm 0.4),-2.2( \pm 0.4) ;(\mathrm{x}, \mathrm{y}, \mathrm{z})]\}$, verified by co-registration of the preoperative MRI and postoperative CT images (Brainlab, München, Germany). Patients and experimenters were not blinded, and each stimulation condition was active for at least $20 \mathrm{~min}$ prior to the recording in order to achieve sufficient efficacy and to limit carry-over effects (Cooper et al., 2013; Weiss et al., 2013). Since the recordings took place in MedOff, we did not consider longer periods.

\section{Kinematic and Electrophysiological Recordings}

During walking, we recorded the synchronized videotapes as well as the kinematic and EMG time series. Therefore, patients wore small, lightweight body-fixed kinematic sensors attached to the left and right ankles (about $20 \mathrm{~mm}$ above the malleolus), and to the lumbar spine (APDM, Portland, OR, United States). Data was sampled at $128 \mathrm{~Hz}$ and transferred to Matlab (Release R2015b, The Mathworks, Inc., Natick, MA, United States) for the post hoc offline analysis. Detailed analyses of the kinematic features and the methodological approach were published elsewhere (Scholten et al., 2017). Briefly, gait kinematics including step length were only analyzed during effective walking, excluding freezing episodes. The events were calculated using the acceleration in the anterior-posterior direction and the angular velocity in the sagittal plane. First we identified the midswing (MS) as peak value exceeding $50^{\circ} \mathrm{s}$ in the sagittal plane of the gyroscope signal. Next we identified toe-off (TO) and heel-strike (HS) in the time interval $750 \mathrm{~ms}$ before and after MS. TO was defined as minimum anterior-posterior acceleration in the time interval before MS, and HS was defined as the minimum value of angular velocity in the sagittal plane before the maximum anteriorposterior acceleration in the time interval after MS. Using the gait events, we computed temporal and spatial gait outcome measures for each condition.

Furthermore, we recorded bipolar EMG with active surface electrodes (actiCAP active Electrodes, Brain Products, Gilching, Germany) of the bilateral TA and GA muscles. We decided to use active electrodes which enabled the digitization of time series at electrode level and, from there, wireless transmission to the electroencephalography (EEG) recorder (EMG was recorded with an EMG input box connected and synchronized to our EEG-recording system), which helped prevent to expose the time series to cable swinging that would arise during gait (MOVE and active electrodes system, Brain Products, Gilching, Germany). The electrophysiological data was sampled at $1 \mathrm{kHz}$. Electrodes of the TA were placed $1 / 3$ below the tip of the fibula on an imaginary line connecting fibula and the medial malleolus, the electrodes of the GA were placed over the most prominent bulge of the inner head. We used an inter electrode distance of $20 \mathrm{~mm}$ in accordance to the SENIAM Guidelines (Hermens et al., 2000).

\section{Clinical Assessments}

All patients reported narrative scores on FoG (NFOG-Q) 1 day prior to the recording. Moreover, we assessed the motor score in UPDRS III in each therapy condition (see Table 1). We deduced the objective freezing-related clinical information from the videos and kinematic survey while walking, i.e., number of freezing episodes, absolute time of freezing and the time percentage frozen (absolute time of freezing throughout the walking task over absolute duration of the walking task, see Table 2, individual parameters see Table 3).

\section{Analyses \\ Data Segmentation, Preprocessing, and Spectral Analysis}

For data analysis we selected the time series while walking straight ahead, and rejected the turning episodes. Next, we segmented for time series related to either 'regular gait' or 'freezing episodes.' 
TABLE 1 | Patient characteristics of the final analysis cohort; NFOG-Q, New Freezing of Gait Questionnaire (Seuthe et al., 2021); STN-DBS, deep brain stimulation of the subthalamic nucleus; SNr-DBS, deep brain stimulation of the substantia nigra pars reticulata.

\begin{tabular}{|c|c|c|c|c|c|c|c|c|c|c|c|c|c|c|c|c|}
\hline \multirow[t]{2}{*}{ ID } & \multirow[t]{2}{*}{ Gender } & \multirow[t]{2}{*}{ Age } & \multirow{2}{*}{$\begin{array}{c}\text { Disease } \\
\text { duration } \\
\text { (years) }\end{array}$} & \multirow{2}{*}{$\begin{array}{l}\text { Months } \\
\text { with } \\
\text { DBS }\end{array}$} & \multirow{2}{*}{$\begin{array}{l}\text { Disease } \\
\text { dominant } \\
\text { side (L/R) }\end{array}$} & \multirow[t]{2}{*}{$\begin{array}{c}\text { NFOG } \\
-Q\end{array}$} & \multirow{2}{*}{$\begin{array}{c}\text { Motor } \\
\text { score (UPDRS } \\
\text { III, item } \\
\text { 18-31) } \\
\text { OFF/STN/ } \\
\text { SNr }\end{array}$} & \multirow[t]{2}{*}{ MMST } & \multicolumn{4}{|c|}{$\begin{array}{l}\text { STN-DBS } \\
\text { parameters }\end{array}$} & \multicolumn{4}{|c|}{$\begin{array}{c}\text { SNr-DBS } \\
\text { parameters }\end{array}$} \\
\hline & & & & & & & & & $\begin{array}{l}\text { Voltage } \\
\text { (left/ } \\
\text { right) }\end{array}$ & $\begin{array}{l}\text { Frequency } \\
(\mathrm{Hz})\end{array}$ & $\begin{array}{c}\text { pulse } \\
\text { width } \\
(\mu \mathrm{s})\end{array}$ & $\begin{array}{l}\text { Active } \\
\text { contacts } \\
\text { (left/ } \\
\text { right) }\end{array}$ & $\begin{array}{l}\text { Voltage } \\
\text { (left/ } \\
\text { right) }\end{array}$ & $\begin{array}{l}\text { Frequency } \\
(\mathrm{Hz})\end{array}$ & $\begin{array}{c}\text { Pulse } \\
\text { width } \\
(\mu \mathrm{s})\end{array}$ & $\begin{array}{c}\text { Active } \\
\text { contacts } \\
\text { (left/ } \\
\text { right) }\end{array}$ \\
\hline 2 & M & 69 & 17 & 13 & L & 13 & $49 / 49 / 49$ & 27 & $2.7 / 3.0$ & 130 & 60 & $\begin{array}{c}2-3+/ \\
10-11+\end{array}$ & $2.5 / 2.5$ & 130 & 60 & $\begin{array}{l}0-1+/ \\
8-9+\end{array}$ \\
\hline 4 & M & 64 & 16 & 86 & L & 4 & 73/40/61 & 30 & $5.3 / 3.0$ & 125 & 60 & $\begin{array}{l}2-3+1 \\
6-7+\end{array}$ & $3.5 / 3.5$ & 125 & 60 & $\begin{array}{l}0-1+/ \\
4-5+\end{array}$ \\
\hline 5 & M & 71 & 16 & 27 & $\mathrm{R}$ & 4 & $50 / 28 / x$ & 30 & $3.6 / 3.6$ & 130 & 60 & $\begin{array}{c}2-3+/ \\
10-11+\end{array}$ & $x / x$ & $x$ & $x$ & $x$ \\
\hline 8 & M & 64 & 9 & 14 & $\mathrm{R}$ & 10 & $50 / 28 / 32$ & 27 & $2.8 / 3.5$ & 130 & 60 & $\begin{array}{c}2-3+/ \\
10-11+\end{array}$ & $2.5 / 1.9$ & 130 & 60 & $\begin{array}{l}0-1+/ \\
8-9+\end{array}$ \\
\hline 9 & F & 56 & 21 & 61 & $\mathrm{R}$ & 4 & $54 / 31 / 40$ & 30 & $5.5 / 3.5$ & 130 & 60 & $\begin{array}{l}2-3+1 \\
6-7+\end{array}$ & $2.9 / 2.9$ & 130 & 60 & $\begin{array}{l}0-1+/ \\
4-5+\end{array}$ \\
\hline 10 & M & 55 & 17 & 4 & $\mathrm{R}$ & 15 & $48 / 28 / 31$ & 28 & $4 / 4.5$ & 130 & 60 & $\begin{array}{c}2-3+/ \\
10-11+\end{array}$ & $2.7 / 2.7$ & 130 & 60 & $\begin{array}{l}0-1+/ \\
8-9+\end{array}$ \\
\hline 13 & F & 76 & 13 & 6 & L & 6 & $46 / 34 / 41$ & 27 & $2.1 / 2.1$ & 125 & 60 & $\begin{array}{c}2-3+/ \\
10-11+\end{array}$ & $1.6 / 1.6$ & 125 & 60 & $\begin{array}{l}0-1+/ \\
8-9+\end{array}$ \\
\hline 14 & $\mathrm{~F}$ & 76 & 19 & 10 & $\mathrm{R}$ & 12 & $38 / 25 / 35$ & 28 & $3.2 / 2.0$ & 130 & 60 & $\begin{array}{c}2-3+/ \\
10-11+\end{array}$ & $2.2 / 2.2$ & 130 & 60 & $\begin{array}{l}0-1+/ \\
8-9+\end{array}$ \\
\hline 15 & M & 67 & 16 & 11 & $\mathrm{R}$ & 7 & $62 / 28 / 67$ & 29 & $5.4 / 5.1$ & 130 & 60 & $\begin{array}{c}2-3+/ \\
10-11+\end{array}$ & $1.3 / 1.3$ & 130 & 60 & $\begin{array}{l}0-1+/ \\
8-9+\end{array}$ \\
\hline
\end{tabular}

In PD 5 electrode contacts did not reach SNr. 
TABLE 2 | Freezing characteristics in different therapeutic conditions.

\begin{tabular}{lcccc}
\hline Condition & $\begin{array}{c}\text { No of } \\
\text { patients }\end{array}$ & $\begin{array}{c}\text { No of freezing } \\
\text { episodes }\end{array}$ & $\begin{array}{c}\text { Absolute time } \\
\text { frozen } \\
\text { (seconds) }\end{array}$ & $\begin{array}{c}\text { Time } \\
\text { percentage } \\
\text { frozen } \\
\text { (\%) }\end{array}$ \\
\hline Off & 4 & 15 & 144 & 39 \\
STN & 1 & 2 & 23 & 31 \\
SNr & 3 & 9 & 172 & 23 \\
\hline
\end{tabular}

Time percentage frozen is given as median value.

We verified FoG episodes from the video recordings according to the existing consensus definition that defines FoG as 'a brief, episodic absence or marked reduction of forward progression of the feet despite the intention to walk' (Nutt et al., 2011), including shuffling episodes as well as complete movement arrests. To entirely remove complete freezing episodes from the 'regular gait' time series, we rejected the clinically defined FoG episode and $1 \mathrm{~s}$ before the episode.

We filtered the EMG data with a band pass finite impulse response filter from 10 to $200 \mathrm{~Hz}$, notch filtered for the $50 \mathrm{~Hz}$ line artifact, and full-wave rectified the EMG time series (Mima and Hallett, 1999).

EMG signals were first partitioned into disjoint segments. Each time segment had a duration of $2 \mathrm{~s}$ resulting in a frequency resolution of $0.5 \mathrm{~Hz}$. Every $200 \mathrm{~ms}$ the power spectral density of the muscular activity was computed of the segment using the fast Fourier transform (FFT; Matlab fft.m function). The FFT returns for each frequency bin a complex number, from which we extract the amplitude by taking the magnitude squared of this number to obtain the power spectral density expressed in $\mu \mathrm{V} 2 / \mathrm{Hz}$. We then averaged over all segments. We report the relative power spectral density after normalizing the absolute values to the summed power from 1 to $45 \mathrm{~Hz}$.

Frequency spectra were computed for TA and GA separately for the left and right leg for PD and HC, as well as for the disease dominant and the non-dominant side separately in PD. Since we did not find statistical differences between the two groups in both comparisons (cluster-based permutation test), we report the average of both legs in all analyses.

\section{Statistical Analysis}

Descriptive are given as mean \pm standard deviation, except for the time percentage frozen given as median value, due to a nonparametric data distribution.

In the first part of our analysis we aimed to compare frequency spectra from 1 to $45 \mathrm{~Hz}$. We decided to explore a broad frequency range of interest based on the fact that (i) frequency domain analysis in ambulatory EMG has only sparsely been studied before, and (ii) in cortical and basal ganglia showed diverse abnormalities in this broad frequency range with regard to motor symptoms, freezing or cognitive processes including the theta, alpha, and also broad beta band (de Hemptinne et al., 2015; Tinkhauser et al., 2017; Anidi et al., 2018; Fischer et al., 2018; Hell et al., 2018; Pozzi et al., 2019). First we compared the frequency spectrum of PD freezers in 'StimOff' and during 'regular gait' with $\mathrm{HC}$ in TA and GA. Furthermore, we compared in PD

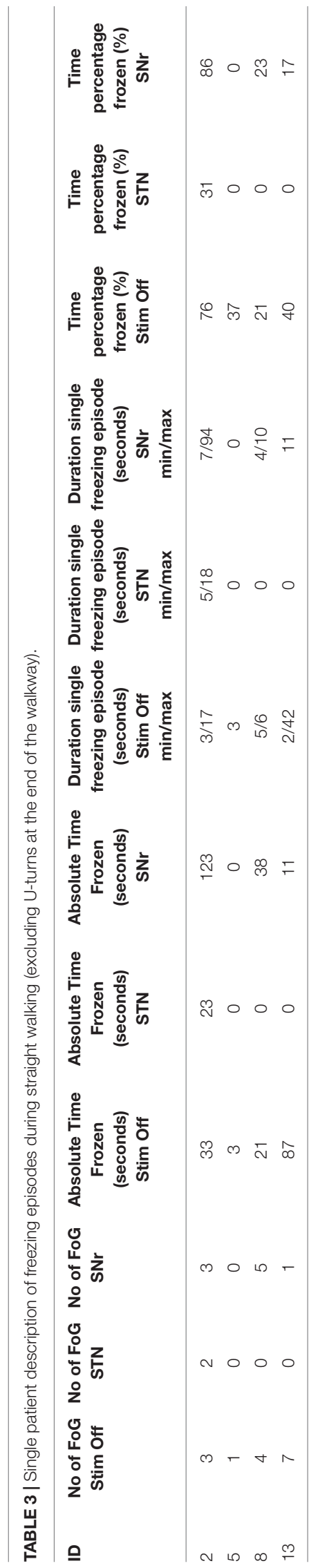


freezers in 'StimOff' the frequency spectra $(1-45 \mathrm{~Hz})$ of 'regular gait' and 'freezing' in TA and GA. Then, we analyzed the effect of stimulation of either target ( $\mathrm{STN}_{\text {only }}, \mathrm{SNr}_{\text {only }}$, respectively) on muscle activity, comparing the frequency domain spectra of $\mathrm{PD}$ freezers in 'regular gait 'StimOff' with 'STN', and 'StimOff' with 'SNr' for TA and GA.

For statistical comparison of the frequency-domain spectra, we used a cluster-based permutation test as implemented in the Fieldtrip toolbox to address for multiple comparisons (Maris and Oostenveld, 2007). This test is based on the Monte Carlo permutation principle and identifies significant changes between conditions using clusters of adjacent frequencies. We performed 5000 randomizations and considered an adjusted two-sided alpha level of $p<0.05$ significant.

\section{Individual Alpha/Low Beta Peak}

Based on the results from the spectral frequency-domain analysis we defined the individual alpha/low beta peak frequency for 'regular gait' as well as for 'freezing' episodes in 'StimOff' in PD freezers. We first identified the peak frequency for TA and GA separately in the frequency range of interest as identified in the cluster analyses. Then, we calculated the individual mean alpha/low-beta peak amplitude of the GA/TA peaks. We used the individual peak frequency from 'freezing' episodes in 'StimOff' to extract the individual alpha/low beta power to compare the differences between 'regular gait' and 'freezing' episodes in PD freezers in 'StimOff.' Additionally the individual alpha/low beta power at the individual peak frequency from 'regular gait' in 'StimOff' was used for statistical comparison of 'StimOff' vs. 'STN', and 'StimOff' vs. 'SNr.' Data were nonparametric distributed and statistical differences were analyzed with a Wilcoxon signed ranks test.

\section{Correlation Analyses}

We correlated spectral measures (individual peak frequency) with clinical outcome parameters such as: FoG (NFOG-Q, UPDRS III item 14 (freezing episodes), number of freezing episodes during straight walking, percentage frozen during the complete walking paradigm. To evaluate the specificity of the observed associations with FoG, we performed control analysis by correlating the spectral measures of other PD motor symptoms including rigidity (UPDRS III item 22) and bradykinesia of the legs (UPDRS III item 26). Correlations were performed for each condition separately (StimOff, STN, and SNr') and calculated with Spearman tests using SPSS 22.0. All tests were decided on a two-sided significance level of $p<0.05$.

\section{RESULTS}

\section{Frequency Domain Analysis of Muscular Activity Healthy Controls vs. Parkinson's Disease in 'Stimulation Off'}

Parkinson's disease patients in 'StimOff' showed higher power of both the TA and the GA compared to HC in the cluster-based statistical comparison from 1 to $45 \mathrm{~Hz}$ during 'regular gait.' In TA, this was represented in the alpha and low-beta range $(6-26.5 \mathrm{~Hz}$; $p=0.0004)$. In GA, it covered a broad frequency range from 6.5 to $45 \mathrm{~Hz}(p=0.0004)$ (Figure 1).

To exclude that the low-frequency cut-off filter $<10 \mathrm{~Hz}$ affected our findings, we added a control analysis, i.e., we recalculated the muscular frequency domain spectra after bandpass filtering from 1 to $200 \mathrm{~Hz}$ (refer Supplementary Figure 1). Statistical analysis revealed similar results: PD patients in 'StimOff' showed higher power of both the TA and the GA compared to $\mathrm{HC}$ in the cluster-based statistical comparison from 1 to $45 \mathrm{~Hz}$ during 'regular gait.' In TA, this was represented in the alpha and low-beta range $(5.5-26 \mathrm{~Hz} ; p=0.0004)$, in GA from 6 to $45 \mathrm{~Hz}(p=0.0004)$.

We asked next, whether the increased activity increase of the alpha and beta band observed in PD freezers in 'StimOff' was related to FoG or to the PD motor 'off state' more generally. To this end, we studied the spectra in 'StimOff' and compared first the frequency domain spectra between 'regular gait' vs. 'freezing' episodes. Then, we studied whether neurostimulation of STN or $\mathrm{SNr}$ modulated the muscular low-frequency activity.

\section{'Regular Gait' vs. 'Freezing Episodes' in 'Stimulation Off'}

The frequency domain spectra pointed to higher activity in both TA and GA during 'freezing' episodes compared to 'regular gait' in 4 PD freezers, however, this did not reach statistical significance in the cluster-based comparison of the frequency domain spectra from 1 to $45 \mathrm{~Hz}$ (TA: $p=0.1264$; GA: $p=0.1204$ ) (Figures 2A,B). When specifically comparing the individual peak maxima of the alpha/low beta frequency range as our main frequency range of interest $(6-26.5 \mathrm{~Hz}$ as derived from our previous analysis PD StimOff vs. HC), we found higher peak maxima in 'freezing' compared to 'regular gait', however, again this did not reach statistical significance (TA: $p=0.250$; GA: $p=0.375$, Wilcoxon signed rank test) (Figures 2C,D).

In further subanalysis we compared 'all freezing episodes', regardless of whether they occurred during regular gait or during a U-turn in 'StimOff' and 'regular gait'. This accounted for 24 freezing episodes in 5 patients and an absolute time frozen of $266 \mathrm{~s}$. Again, the frequency domain spectra pointed to higher activity in both TA and GA during 'all freezing episodes' compared to 'regular gait', however, this did not reach statistical significance in the cluster-based comparison of the frequency domain spectra from 1 to $45 \mathrm{~Hz}$ (TA: $p=0.7030$; GA: $p=0.2244$ ) (Figures 2E,F).

\section{'Subthalamic Nucleus' or 'Substantia Nigra Pars Reticulate' vs. 'Stimulation Off'}

Next, we studied whether muscular activity during 'regular gait' in 'StimOff' was modulated by either 'STN' or 'SNr' stimulation. STN showed lower activity in TA between 5 and $21 \mathrm{~Hz}$ and in GA from 7 to $23 \mathrm{~Hz}$, however this did not reach statistical significance in the cluster-based comparison from 1 to $45 \mathrm{~Hz}$ ('StimOff' vs. 'STN': TA: $p=0.6111$, GA: $p=0.8362$; 'StimOff' vs. 'SNr': TA: $p=0.3639, \mathrm{GA}: p=0.1784$ ) (Figures 3A-D).

As derived from the contrast PD StimOff vs. HC, we further analyzed as additional non-parametric analysis the individual 

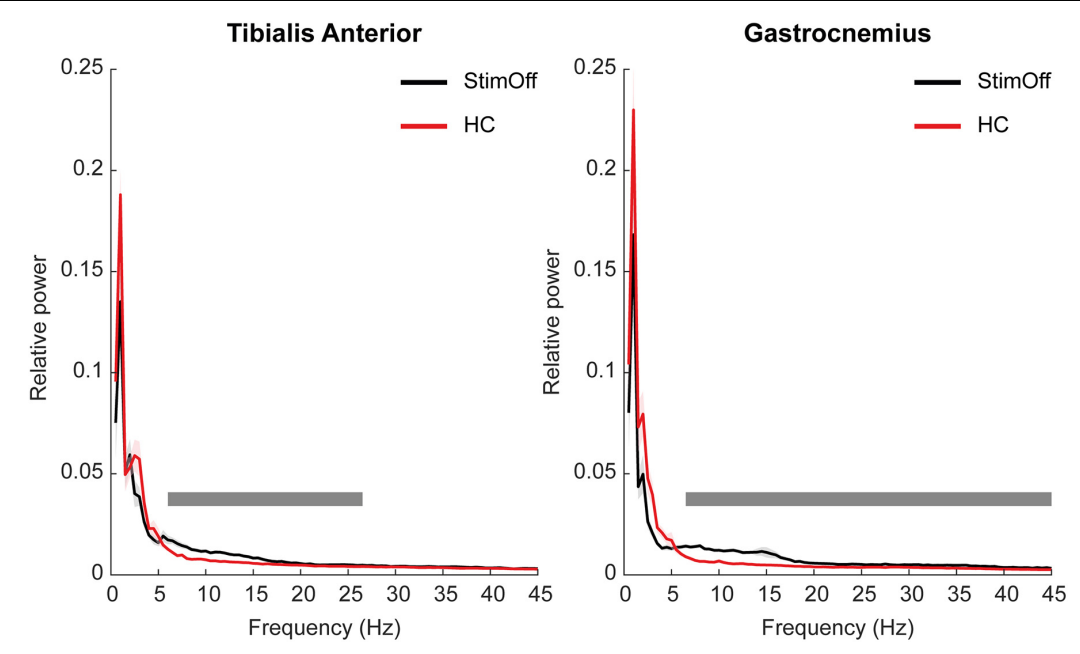

FIGURE 1 | Power spectrum and standard error of the mean (SEM) of TA (A, left panel) and GA (B, right panel) during 'regular gait' in 9 PD patients with DBS turned off ('StimOff') and healthy controls (HC). PD patients in 'StimOff' showed higher power of TA in the alpha and low-beta range (6-26.5 Hz; $p=0.0004)$ and a higher power in the GA muscle (6.5-45 Hz; $p=0.0004$, cluster based permutation test).

peak maxima from 6 to $26.5 \mathrm{~Hz}$. We found that 'STN' (TA: $p=0.015, \mathrm{GA}: p=0.015$, Wilcoxon signed rank test), but not ' $\mathrm{SNr}$ ' (TA: $p=0.093$, GA: $p=0.161$ ) decreased the peak maxima in the alpha/low-beta range in both TA and GA compared to 'StimOff' (Figures 4A-D).

\section{Correlations of Alpha/Low-Beta Peak Maxima With Clinical Motor Scores and Freezing of Gait Measures}

We correlated the individual alpha/low beta peak maxima in 'StimOff' with clinical measures of FoG and control variables. As freezing measures there was a correlation of time percentage frozen and the alpha/low-beta peak maxima of the GA in 'StimOff' ( $r=0.763, p=0.017$, uncorrected; Figure 5) but not of the TA $(p=0.631)$. There was no correlation of NFOG-Q (TA: $p=0.439$; GA: $p=0.841$ ), UPDRS III freezing (item 14) (TA: $p=0.489$, GA: $p=0.768$ ), and the number of FoG episodes (TA: $p=0.452$, GA: $p=0.965)$. As control analyses, we did not find correlations with rigidity (UPDRS III item 22) (TA: $p=0.795$, GA: $p=0.931$ ) and diadochokinesia (UPDRS III item 26) (TA: $p=0.628$, GA: $p=0.742$ ).

\section{Gait Characteristics}

On average, HC walked for $198 \pm 55$ s (mean \pm standard deviation) with a cadence of $105 \pm 10$ steps per minute and a step length of $0.46 \pm 0.05 \mathrm{~m}$. PD patients in 'StimOff' walked on average $126 \pm 53 \mathrm{~s}$ with a cadence of $106 \pm 16$ steps per minute and a step length of $0.23 \pm 0.09 \mathrm{~m}$. In 'STN', PD patients walked on average $157 \pm 36 \mathrm{~s}$ with a cadence of $101 \pm 15$ steps per minute and a step length of $0.28 \pm 0.08 \mathrm{~m}$. In 'SNr', PD patients walked $151 \pm 57 \mathrm{~s}$, with a cadence of $108 \pm 18$ steps per minute, and a step length of $0.21 \pm 0.08 \mathrm{~m}$.

We performed a statistical comparison that revealed significant differences in stride length between $\mathrm{HC}$ and $\mathrm{PD}$ in 'StimOff' ( $p=0.00006$, Mann-Whitney- $U$-Test). Since gait speed is known to have an impact on additional kinematic parameters (Fukuchi et al., 2019), we additionally calculated the over ground walking speed in HC: $0.7 \pm 0.1 \mathrm{~m} / \mathrm{s}$, and in PD in 'StimOff': $0.4 \pm 0.1 \mathrm{~m} / \mathrm{s}$ ( $p=0.00007$, Mann-Whitney- $U$-Test), which also differed significantly between the two groups. These kinematic differences might also affect underlying electrophysiological differences between HC and PD in 'StimOff.' Therefore, we correlated individual gait speed to (i) the frequency of the individual alpha peak $(\rho=-0.51, p=0.16)$ and (ii) to the relative power of the individual alpha peak (both muscles: $\rho=-0.42$, $p=0.26$; TA $\rho=-0.07, p=0.87$; GA $\rho:-0.45, p=0.13)$. All correlations were negative and do not suggest that lower EMG power relates to gait speed.

\section{DISCUSSION}

In this study, we studied PD freezers while walking with ambulatory EMG-recordings of the antagonistic leg muscles. We found that PD freezers showed enhanced activity of TA and GA in a low frequency range of alpha and beta band, presumably in both TA and GA compared to HC during regular walking. Furthermore PD freezers showed a similar activation profile during regular walking and actual freezes. Interestingly, STN stimulation decreased this pathological activity together with improved clinical outcomes in freezing.

\section{Pathological Muscular Activity and Its Relation to Freezing in Parkinson's Disease}

In healthy people EMG activity of hand movement and fine motor task is mostly located in the beta band $(15-30 \mathrm{~Hz})$ or Piper rhythm (35-60 Hz) (Brown, 2000), in contrast to PD patients, who showed predominant activation around or below $10 \mathrm{~Hz}$ in EMG in dopaminergic off state. Effective L-Dopa or STNDBS therapy lead to suppression of this pathological activity (Salenius et al., 2002; Weiss et al., 2012). However, the relation of these activation abnormalities to PD gait remained unknown. 

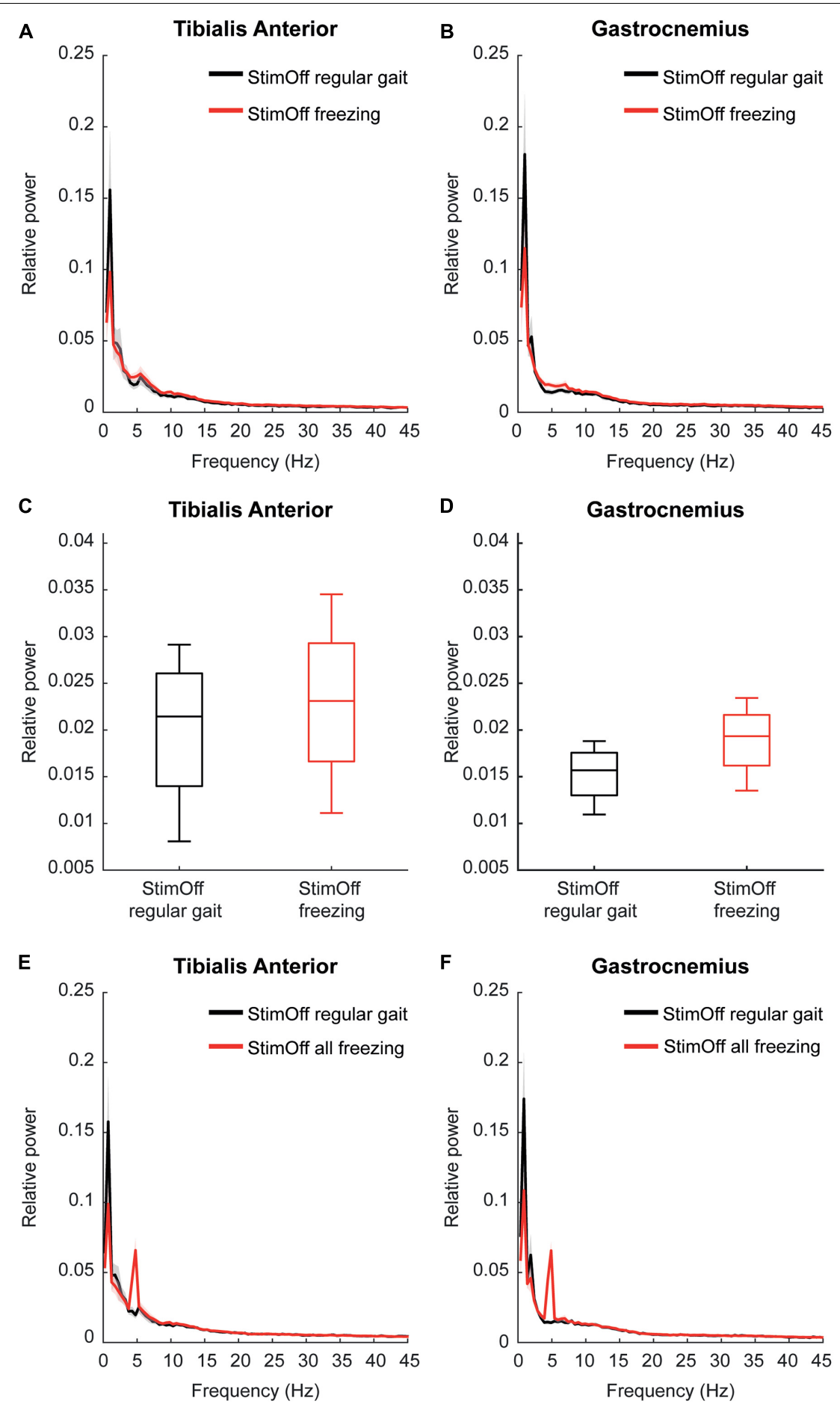

FIGURE 2 | (A,B) Power spectrum and SEM of TA (upper left panel) and GA (upper right panel) in 4 PD patients with 'StimOff' comparing 'regular gait' and 'freezing.' Freezing episodes showed higher median power in TA and GA between 5 and $10 \mathrm{~Hz}$, however, this difference did not show significance and has to be considered with caution owing to the limited number of patients showing freezing episodes during straight walking. (C,D) Alpha/low-beta power observed in 'StimOff' during regular gait and freezing episodes in TA (middle left panel) and GA (middle right panel). There was no significant difference between the two conditions. Data is presented in boxplots giving the median, 25, 75th percentile, min and max. (E,F) Power spectrum and SEM of TA (lower left panel) and GA (lower right panel) in 5 PD patients with 'StimOff' comparing 'regular gait' and ' all freezing' episodes. Freezing episodes showed higher median power in TA and GA between 5 and $10 \mathrm{~Hz}$ however, this difference did not show significance and has to be considered with caution owing to the limited number of patients showing freezing episodes. Please note the prominent peak at $5 \mathrm{~Hz}$ in TA and GA. Visual inspection of the video recordings as well as of the EMG raw data did not reveal tremor-associated activation. Further, the individual frequency spectra of the 5 subjects did not show similar peak activation but a broader low-frequency activation band known from freezing episodes (Moore et al., 2008; Vercruysse et al., 2012) as opposed to tremor that occurs in a stable circumscribed frequency bin in the individual subject. 


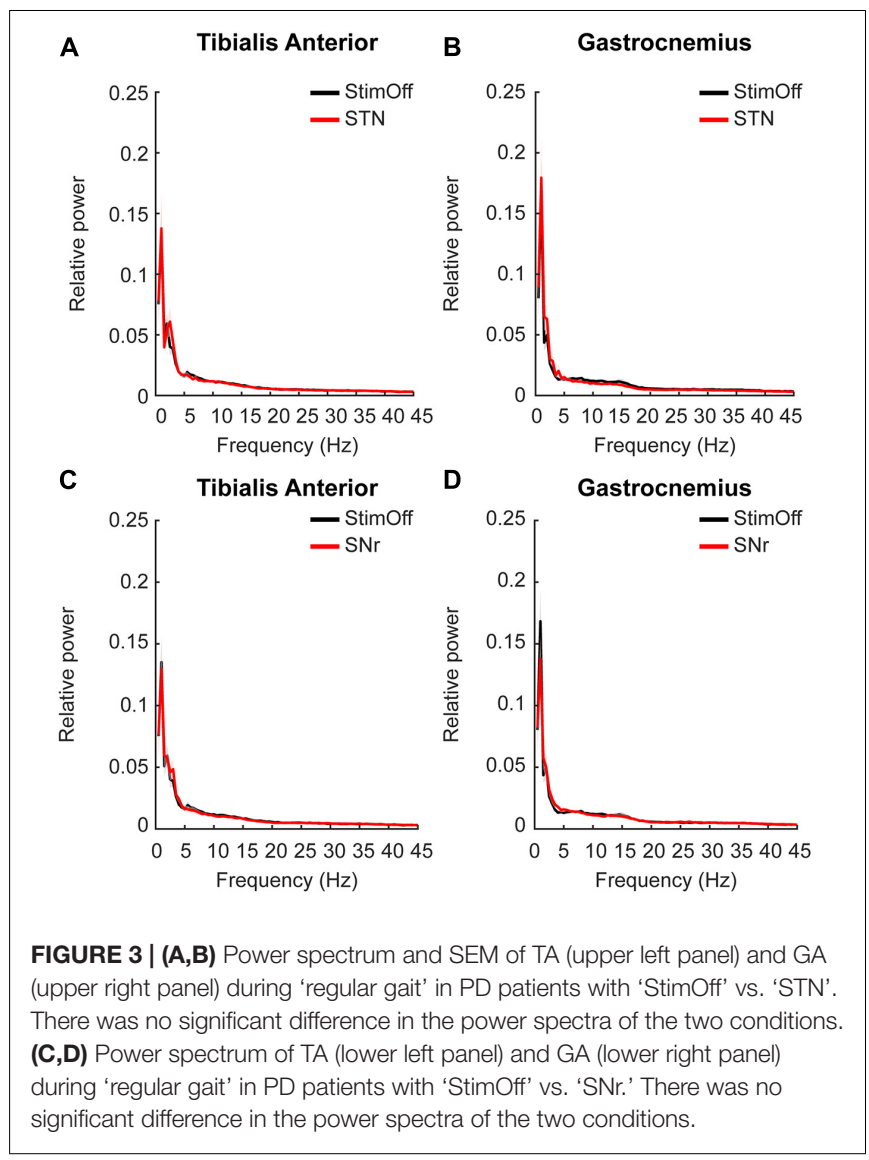

We found that PD freezers show elevated activity from 6 to $45 \mathrm{~Hz}$ in the antagonistic leg muscles during effective regular gait, and this was centered in the low frequency range of the alpha and low beta bands. This was present during both regular gait and during the freezes to similar extent. Since the activity was not specific to the freeze itself but existed already during preserved gait, muscular activation at lower frequency around and below $10 \mathrm{~Hz}$ may be a general feature of the PD off state mirroring pathological supraspinal activation patterns on the level of the spinal cord (Salenius et al., 2002; Weiss et al., 2012; Flood et al., 2019).

Nevertheless, the finding raises considerations on whether activation at lower frequency contributes to freezing, such that it could represent a more unstable motor system which yields susceptibility to encounter freezing episodes (Scholten et al., 2016b). Activation abnormalities around and below $10 \mathrm{~Hz}$ were identified as a pathological feature of the multistage locomotor network comprising cortex (Marsden et al., 2001; Scholten et al., 2016a), basal ganglia (Hammond et al., 2007; de Solages et al., 2010; Chen et al., 2019), brainstem (Thevathasan et al., 2012), and spinal pattern generator (Marsden et al., 2001; Weiss et al., 2012; Scholten et al., 2016a). From these data and the present study it is plausible to reason that these activation abnormalities relate to freezing, since freezers show premonitory activation abnormalities already outside or immediately preceding a freeze in contrast to non-freezers (Singh et al., 2013; Toledo et al., 2014; Storzer et al., 2017). Instability of the motor system may be a pre-requisite to freezing there mirroring the susceptibility of a

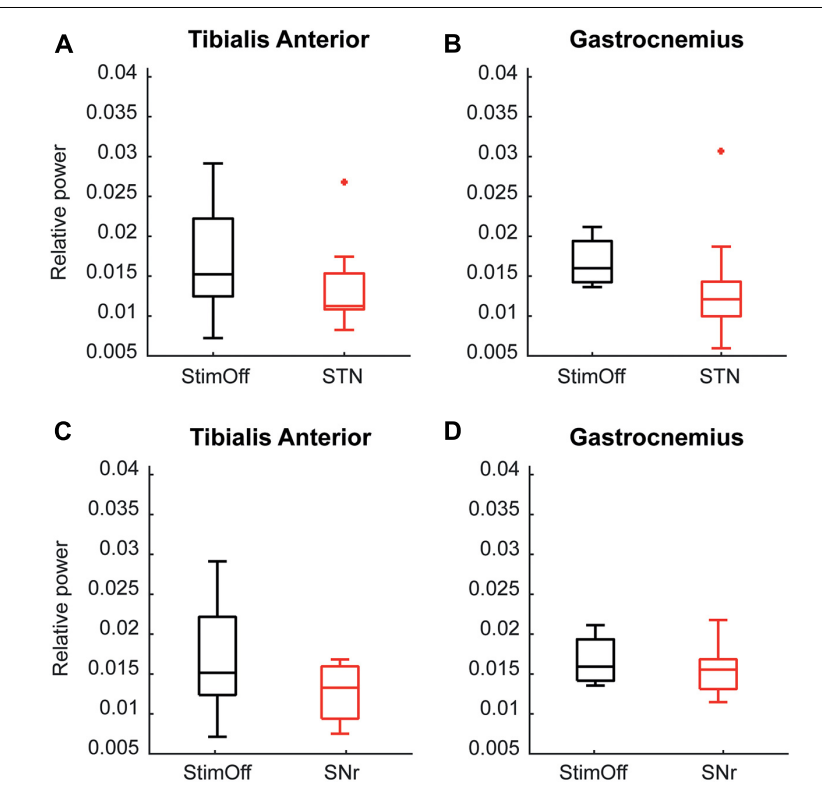

FIGURE 4 | (A,B) Data is presented in boxplots giving the median, 25th, 75th percentile, min and max. Alpha/low beta power observed in 'StimOff' can be significantly lowered by 'STN' in both the TA (upper left panel, $p=0.015$ ) and GA (upper right panel, $p=0.015)$. (C,D) Data is presented in boxplots giving the median, 25th, 75th percentile, min and max. There was no significant difference of the alpha/low beta power observed in 'StimOff' vs. 'SNr' in both the TA (lower left panel) and GA (lower right panel). ${ }^{+}$Indicates statistically significat differences.

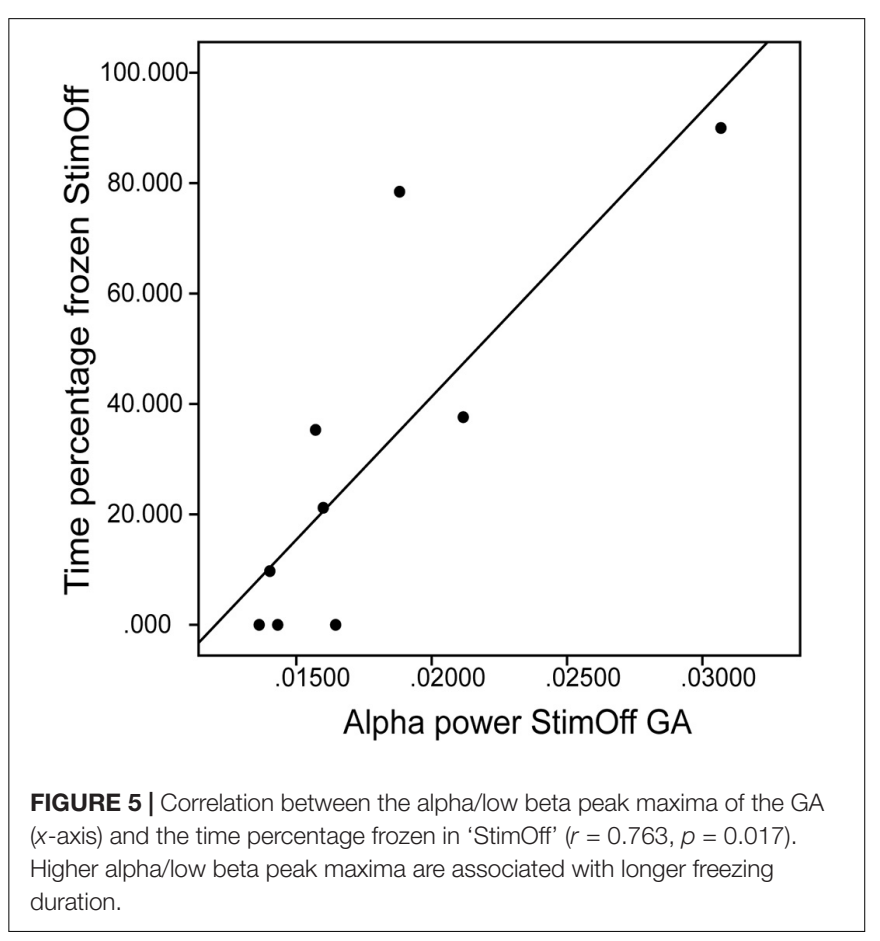

PD patient to loose effective spinal motor output (Scholten et al., 2016b, 2020). During a freeze itself, the pathological rhythm can either stay unchanged or even increase (Scholten et al., 2016a; Anidi et al., 2018; Chen et al., 2019; Pozzi et al., 2019). 
In this sense, we speculate that low-frequency activation of the spinal pattern generator of PD freezers could be interpreted as an abnormally slow and prominent rhythm. This might oppose the rapid adjustment of antagonistic muscle activity as is needed for the recurrent cycling of activation and deactivation cascades throughout the cyclic gait phases. Mathematically spoken, motor output in the high beta and gamma range $>20 \mathrm{~Hz}$ would allow for much faster reprogramming and adaptation of the spinal pattern generator (Schoffelen et al., 2005) as opposed to the activation abnormalities at slower rhythms observed in this freezer group. This would lead - depending on the individual cadence - to a much slower adaptation and also performance of the alternating activation - deactivation changes of the antagonistic leg muscles throughout the full gait cycle, which can only interact in the slow alpha and low-beta rhythms in PD. In healthy subjects activation of the TA will take for about $10 \%$ of the gait cycle, from initiation to full recruitment (Hart et al., 2006). Considering a cadence of around 105 steps per minute in our cohort of healthy controls indicates a duration of the gait cycle of $0.57 \mathrm{~s}$ and a necessity of adaptions within $57 \mathrm{~ms}$. The prominent slow alpha and low-beta rhythms in PD patients will not allow for more than a temporal resolution of around $50-100 \mathrm{~ms}$, which is inherently slow to allow rapid adjustments of the gait cycles and leads to abnormal temporal activation patterns in PD freezers (Nieuwboer et al., 2004). Moreover, the ability to adapt gait to the external or internal requirements is limited at such slow frequencies, and this may comply with the clinical observation that gait performance can be disrupted with cognitive interference (Nutt et al., 2011; Nonnekes et al., 2015). Instead, it was stabilized with rhythmic cueing, as was the oscillatory beta activity time-locked to the gait cycle (Fischer et al., 2018).

Besides the enhanced alpha and low beta activity our data also reveal higher power spectra $>20 \mathrm{~Hz}$ in GA, which could be due to (i) either postural differences in PD patients, caused by a more flexed posture (Nieuwboer et al., 2004) and a tendency to shift the center of gravity forward when walking, resulting in toe walking or (ii) reflect compensatory mechanisms caused by cortical drives to the spinal cord which are located in a higher frequency range (Schoffelen et al., 2005). To this point it is rather difficult to disentangle whether this high frequency activation in GA is a causal or compensatory mechanism in the first place.

\section{Subthalamic Stimulation Reduces Muscle Activation at Low Frequencies and Clinical Freezing Outcomes}

Subthalamic nucleus -stimulation in PD is a potent treatment for L-Dopa sensitive FoG. Clinical studies reported on reduced occurrence of FOG and sever falls in PD freezers after undergoing STN-DBS (Schlenstedt et al., 2017; Barbe et al., 2020; Cebi et al., 2020). However, to prevent adverse outcomes of STN-DBS it is important to avoid co stimulation of the pallido-thalamic tract crossing on the level of the zona incerta as was for example found in antero-medially displaced electrodes or by delivering large amounts of energy and increasing the electrical field (Moreau et al., 2008; Fleury et al., 2016). When applying effective STNstimulation along with clinical improvement also pathological changes of gait parameters in PD freezers, such as stride length and stride amplitude improve (Pötter-Nerger and Volkmann, 2013; Scholten et al., 2017). Notably, high frequency stimulation of the STN also led to a reduction of beta-band activity in STNLFPs. In our experiment the kinematic parameters do not reveal significant differences between 'STN' and 'StimOff.' Scholten et al. (2017) report results of a larger group of PD freezers in which gait parameters, temporal and spatial, showed improvement with STN- or SNr-stimulation. Especially the stride length improved when applying STN-DBS. In the subgroup we choose for our data analysis also the stride length improves in STN-condition, but the changes are not statistically significant, probably due to the smaller size of the cohort. Additionally also the absolute number of freezing episodes across subjects and the absolute time frozen improved when we applied STN-DBS in contrast to the 'StimOff'condition, and this clinical improvement was associated with a reduction of pathological activity at low frequency in TA and GA. The modulation effect on oscillatory patterns of STN-DBS is not locally limited to the STN, but may impact on the functionally connected areas, in particular the subthalamo-cortical circuits (de Hemptinne et al., 2015; Weiss et al., 2015). On the one hand STN has an excitatory net effect on $\mathrm{SNr}$ and GPi, resulting in more inhibitory control on PPN/MLR which was brought in context to FoG (Shine et al., 2013; Weiss et al., 2019). STN-DBS is attenuating the exaggerated glutamatergic output (Benabid et al., 2003) and the pathological beta oscillations (Kühn et al., 2008; Eusebio et al., 2012). This means that STN-DBS could potentially act on releasing the pallidothalamic inhibition of the primary motor cortex, or by modulating the cortex more directly via the hyperdirect connections. However, toning down pathological STN activity could also change SNr activity through the monosynaptic connections (Milosevic et al., 2018; Weiss et al., 2019). Thus, observing a change of muscular activity with STNDBS would not necessarily mean that the effect is transmitted via the 'ascending' cortical and then corticospinal pathway, but would still allow for contributions of the 'descending' nigropontine route. However, our second finding that $\mathrm{SNr}_{\text {mono }}$ stimulation did not affect both muscular activity and clinical FoG measures argues against this alternative interpretation. Therefore, we propose that the primary effect of high-frequency STN-DBS was delivered via the subthalamo-cortical circuits of either the indirect or the hyperdirect pathway - or maybe both (Gradinaru et al., 2009; de Hemptinne et al., 2015). STN holds projections via the subthalamo-pallido-cortical 'hyperdirect' and the striato-external pallido-subthalamo-internal pallidocortical 'indirect' pathway, both executing inhibitory control on thalamo-cortical activation patterns and preventing effective motor output (Delwaide et al., 2000). STN-DBS can effectively modulate the oscillatory patterns of cortical areas via these pathways and electrophysiological changes are accompanied by improved clinical outcome parameters (Kuriakose et al., 2010; de Hemptinne et al., 2015; Weiss et al., 2015). Considering the fact that in our experiment clinical as well as oscillatory improvements were achieved via STN-DBS, but not SNr-DBS, it seems reasonable to consider the underlying pathological 
enhance alpha and low beta activity also being primary transmitted via the subthalamo-cortical pathway and the descending projections of the pyramidal tract to spinal motor neurons. Further support for this hypothesis comes from studies on the pathology of ULF, when freezing episodes were associated with increased cortical activity $(7-11 \mathrm{~Hz})$, muscular activity (6$9 \mathrm{~Hz}$ ), and increased intermuscular coherence, the latter of which was proposed as marker for cortical control of muscular activity (Scholten et al., 2016a). Nevertheless, cortical contributions do not exclude subcortical contributions to muscular activation at low frequencies. Future research using combined EMG-LFP-EEG measurement in gait paradigms will help to further investigate the underlying network interactions of pathological activation pattern in FoG (Kühn et al., 2009; Lewis and Barker, 2009; Anidi et al., 2018; Pozzi et al., 2019). Especially high resolution timefrequency analyses of LFP-EEG data could help differentiate a primary cortical or subcortical source of the muscular activation abnormalities of the alpha and beta band.

\section{Methodological Considerations}

In this study, we investigated the role of muscular activation abnormalities at alpha and beta frequencies for FoG taking advantage from ambulatory EMG recordings, and studied their supraspinal modulation with STN- and SNr-DBS. We were able to analyze data from a very homogenous group of finally 9 PD freezers with an acinetic-rigid subtype, susceptibility of FoG and electrode localization of the most caudal contact being located in $\mathrm{SNr}$, a group size comparable to those of previous electrophysiological studies (Anidi et al., 2018; Pozzi et al., 2019). Although observing a large quantity of freezes under laboratory conditions has been recognized as a challenge in FoG research (Lewis and Shine, 2016; Weiss et al., 2019) we were able to gather an absolute time of $144 \mathrm{~s}$ frozen in 'StimOff,' which can be considered sufficient data material to stabilize the frequency domain spectra from a statistical viewpoint (Mima and Hallett, 1999). A limitation is that the data of freezing episodes stem from only 5 of the 9 subjects which limits the interpretation and generalizability of comparing the spectra of the freezing state with regular gait. The same applies for comparisons of clinical features, i.e., number of freezing episodes, absolute time frozen, etc. The descriptive indicate a marked reduction of freezing, considering the number of patients expressing FoG (4 in 'StimOff', 1 in 'STN'), the number of freezing episodes (15 in 'StimOff', 2 in 'STN') and the absolute time frozen (144 s in 'StimOff', $50 \mathrm{~s}$ in 'STN'). Still the subgroup is quite small and performing a Wilcoxon signed rank test would not show statistical significant improvement. But we were therefore careful in interpreting our finding, and suggest to leave it to future studies to test, whether muscular activity shows a further increase during freezes as compared to regular gait. Nevertheless, the above summarized evidence across the distributed freezing-network levels draws a coherent picture that activation around and below $10 \mathrm{~Hz}$ in basal ganglia, brainstem, cortex, and spinal motor neurons is critical to freezing susceptibility, i.e., representing a general failure of neuronal gait integration in PD freezers that yield a risk for expressing freezing episodes on this grounds.

We performed several correlation analyses of clinical measurements and electrophysiological parameters. There was no correction for multiple comparisons, since we performed the correlation analysis with exploratory intent and did not interpret them in a confirmatory way. Instead, we suggest to reproduce these findings in independent and larger cohorts.

\section{CONCLUSION}

Here, we demonstrated with ambulatory EMG that PD freezers in medication off and stimulation off show abnormal activation of alpha and low-beta band activity when compared with healthy subjects. This was not specific to the freezing state. However, our findings and the context to the available research support that activation abnormality contributes to freezing susceptibility, since STN-DBS decreased the muscular activity together with clinical improvement of FoG. Since we found that STN-DBS but not SNr-DBS was effective to suppress this low-frequency activity, it is likely that the cortical projections of the STN rather than the brainstem connections albeit not being exclusive were meaningful to this effect. Future combined LFP-EEG-EMG research may shed further light on the neuronal supraspinal contributions to muscular activation abnormalities.

\section{DATA AVAILABILITY STATEMENT}

The data analyzed in this study is subject to the following licenses/restrictions: privacy policy of individual patients' data. Requests to access these datasets should be directed to DW, daniel.weiss@med.uni-tuebingen.de.

\section{ETHICS STATEMENT}

The studies involving human participants were reviewed and approved by Ethik-Kommission am Universitätsklinikum Tübingen. The patients/participants provided their written informed consent to participate in this study.

\section{AUTHOR CONTRIBUTIONS}

MS, AG, and DW: conception and design of the study. MS and JK: acquisition of data. IC: patient inclusion. MS, M-SB, and DW: analysis and interpretation of data. M-SB and DW: drafting the manuscript. All authors: critical revision and final approval of the version to be submitted.

\section{FUNDING}

This work was supported by Deutsche Forschungsgesellschaft with grant numbers WE5375/1-1 and WE5375/1-3.

\section{SUPPLEMENTARY MATERIAL}

The Supplementary Material for this article can be found online at: https://www.frontiersin.org/articles/10.3389/fnhum. 2021.733067/full\#supplementary-material 
Supplementary Figure 1 | Power spectrum and standard error of the mean (SEM) of TA (left panel) and GA (right panel) during 'regular gait' in 9 PD patients with DBS turned off ('StimOff') and healthy controls $(\mathrm{HC})$ after band pass

\section{REFERENCES}

Anidi, C., O’Day, J. J., Anderson, R. W., Afzal, M. F., Syrkin-Nikolau, J., Velisar, A., et al. (2018). Neuromodulation targets pathological not physiological beta bursts during gait in Parkinson's disease. Neurobiol. Dis. 120, 107-117. doi: 10.1016/j.nbd.2018.09.004

Barbe, M. T., Tonder, L., Krack, P., Debu, B., Schüpbach, M., Paschen, S., et al. (2020). Deep brain stimulation for freezing of gait in Parkinson's disease with early motor complications. Mov. Disord. 35, 82-90. doi: 10.1002/mds.27892

Benabid, A. L., Piallat, B., Wallace, B., Benazzouz, A., Lenart, D., Andressen, C., et al. (2003). Might deep brain stimulation of the subthalamic nucleus beneuroprotective in patients with Parkinson's disease? Thalamus Related Syst. 2, 95-102.

Breit, S., Bouali-Benazzouz, R., Benabid, A. L., and Benazzouz, A. (2001). Unilateral lesion of the nigrostriatal pathway induces an increase of neuronal activity of the pedunculopontine nucleus, which is reversed by the lesion of the subthalamic nucleus in the rat. Eur. J. Neurosci. 14, 1833-1842. doi: 10.1046/j.0953-816x. 2001.01800.x

Breit, S., Lessmann, L., Unterbrink, D., Popa, R. C., Gasser, T., and Schulz, J. B. (2006). Lesion of the pedunculopontine nucleus reverses hyperactivity of the subthalamic nucleus and substantia nigra pars reticulata in a 6hydroxydopamine rat model. Eur. J. Neurosci. 24, 2275-2282. doi: 10.1111/j. 1460-9568.2006.05106.x

Brown, P. (2000). Cortical drives to human muscle: the Piper and related rhythms. Prog. Neurobiol. 60, 97-108. doi: 10.1016/s0301-0082(99)00029-5

Brown, P. (2003). Oscillatory nature of human basal ganglia activity: relationship to the pathophysiology of Parkinson's disease. Mov. Disord. 18, 357-363. doi: $10.1002 / \mathrm{mds} .10358$

Burbaud, P., Bonnet, B., Guehl, D., Lagueny, A., and Bioulac, B. (1998). Movement disorders induced by gamma-aminobutyric agonist and antagonist injections into the internal globus pallidus and substantia nigra pars reticulata of the monkey. Brain Res. 780, 102-107. doi: 10.1016/s0006-8993(97)01158-x

Cebi, I., Scholten, M., Gharabaghi, A., and Weiss, D. (2020). Clinical and kinematic correlates of favorable gait outcomes from subthalamic stimulation. Front. Neurol. 11:212. doi: 10.3389/fneur.2020.00212

Chen, C. C., Yeh, C. H., Chan, H. L., Chang, Y. J., Tu, P. H., Yeh, C. H., et al. (2019). Subthalamic nucleus oscillations correlate with vulnerability to freezing of gait in patients with Parkinson's disease. Neurobiol. Dis. 132:104605. doi: 10.1016/j.nbd.2019.104605

Cooper, S. E., McIntyre, C. C., Fernandez, H. H., and Vitek, J. L. (2013). Association of deep brain stimulation washout effects with Parkinson disease duration. JAMA Neurol. 70, 95-99. doi: 10.1001/jamaneurol.2013.581

de Hemptinne, C., Swann, N. C., Ostrem, J. L., Ryapolova-Webb, E. S., San Luciano, M., Galifianakis, N. B., et al. (2015). Therapeutic deep brain stimulation reduces cortical phase-amplitude coupling in Parkinson's disease. Nat. Neurosci. 18, 779-786. doi: 10.1038/nn.3997

de Solages, C., Hill, B. C., Koop, M. M., Henderson, J. M., and Bronte-Stewart, H. (2010). Bilateral symmetry and coherence of subthalamic nuclei beta band activity in Parkinson's disease. Exp. Neurol. 221, 260-266. doi: 10.1016/j. expneurol.2009.11.012

Delwaide, P. J., Pepin, J. L., De Pasqua, V., and de Noordhout, A. M. (2000). Projections from basal ganglia to tegmentum: a subcortical route for explaining the pathophysiology of Parkinson's disease signs? J. Neurol. 247(Suppl. 2), II75-II81. doi: 10.1007/pl00007765

Drew, T., Prentice, S., and Schepens, B. (2004). Cortical and brainstem control of locomotion. Prog. Brain Res. 143, 251-261. doi: 10.1016/S0079-6123(03)4 3025-2

Ehgoetz Martens, K. A., Shine, J. M., Walton, C. C., Georgiades, M. J., Gilat, M., Hall, J. M., et al. (2018). Evidence for subtypes of freezing of gait in Parkinson's disease. Mov. Disord. 33, 1174-1178. doi: 10.1002/mds.27417

Eusebio, A., Cagnan, H., and Brown, P. (2012). Does suppression of oscillatory synchronisation mediate some of the therapeutic effects of DBS in patients with Parkinson's disease? Front. Integr. Neurosci. 6:47. doi: 10.3389/fnint.2012.00047 filtering of $1-200 \mathrm{~Hz}$. PD patients in 'StimOff' showed higher power of TA in the alpha and low-beta range $(5.5-26 \mathrm{~Hz} ; p=0.0004)$ and a higher power in the GA muscle (6-45 Hz; $p=0.0004$, cluster based permutation test).

Ferraye, M. U., Debu, B., Fraix, V., Goetz, L., Ardouin, C., Yelnik, J., et al. (2010). Effects of pedunculopontine nucleus area stimulation on gait disorders in Parkinson's disease. Brain 133(Pt 1), 205-214. doi: 10.1093/brain/ awp229

Fischer, P., Chen, C. C., Chang, Y. J., Yeh, C. H., Pogosyan, A., Herz, D. M., et al. (2018). Alternating modulation of subthalamic nucleus beta oscillations during stepping. J. Neurosci. 38, 5111-5121. doi: 10.1523/JNEUROSCI.3596-17.2018

Fleury, V., Pollak, P., Gere, J., Tommasi, G., Romito, L., Combescure, C., et al. (2016). Subthalamic stimulation may inhibit the beneficial effects of levodopa on akinesia and gait. Mov. Disord. 31, 1389-1397. doi: 10.1002/mds.26545

Flood, M. W., Jensen, B. R., Malling, A. S., and Lowery, M. M. (2019). Increased EMG intermuscular coherence and reduced signal complexity in Parkinson's disease. Clin. Neurophysiol. 130, 259-269. doi: 10.1016/j.clinph.2018.10.023

Fukuchi, C. A., Fukuchi, R. K., and Duarte, M. (2019). Effects of walking speed on gait biomechanics in healthy participants: a systematic review and metaanalysis. Syst. Rev. 8:153. doi: 10.1186/s13643-019-1063-z

Garcia-Rill, E., Saper, C. B., Rye, D. B., Kofler, M., Nonnekes, J., Lozano, A., et al. (2019). Focus on the pedunculopontine nucleus. Consensus review from the May 2018 brainstem society meeting in Washington, DC, USA. Clin. Neurophysiol. 130, 925-940. doi: 10.1016/j.clinph.2019.03.008

Gradinaru, V., Mogri, M., Thompson, K. R., Henderson, J. M., and Deisseroth, K. (2009). Optical deconstruction of parkinsonian neural circuitry. Science 324, 354-359. doi: 10.1126/science.1167093

Guertin, P. A. (2009). The mammalian central pattern generator for locomotion. Brain Res. Rev. 62, 45-56.

Hammond, C., Bergman, H., and Brown, P. (2007). Pathological synchronization in Parkinson's disease: networks, models and treatments. Trends Neurosci. 30, 357-364. doi: 10.1016/j.tins.2007.05.004

Hart, D. J., Taylor, P. N., Chappell, P. H., and Wood, D. E. (2006). A microcontroller system for investigating the catch effect: functional electrical stimulation of the common peroneal nerve. Med. Eng. Phys. 28, 438-448.

Heilbronn, M., Scholten, M., Schlenstedt, C., Mancini, M., Schöllmann, A., Cebi, I., et al. (2019). Anticipatory postural adjustments are modulated by substantia nigra stimulation in people with Parkinson's disease and freezing of gait. Parkinsonism Relat. Disord. 66, 34-39. doi: 10.1016/j.parkreldis.2019.06.023

Hell, F., Plate, A., Mehrkens, J. H., and Bötzel, K. (2018). Subthalamic oscillatory activity and connectivity during gait in Parkinson's disease. Neuroimage Clin. 19, 396-405. doi: 10.1016/j.nicl.2018.05.001

Hermens, H. J., Freriks, B., Disselhorst-Klug, C., and Rau, G. (2000). Development of recommendations for SEMG sensors and sensor placement procedures. J. Electromyogr. Kinesiol. 10, 361-374. doi: 10.1016/s1050-6411(00)00027-4

Jordan, L. M., Liu, J., Hedlund, P. B., Akay, T., and Pearson, K. G. (2008). Descending command systems for the initiation of locomotion in mammals. Brain Res. Rev. 57, 183-191. doi: 10.1016/j.brainresrev.2007.07.019

Kühn, A. A., Kempf, F., Brücke, C., Gaynor Doyle, L., Martinez-Torres, I., Pogosyan, A., et al. (2008). High-frequency stimulation of the subthalamic nucleus suppresses oscillatory beta activity in patients with Parkinson's disease in parallel with improvement in motor performance. J. Neurosci. 28, 6165-6173. doi: 10.1523/JNEUROSCI.0282-08.2008

Kühn, A. A., Kupsch, A., Schneider, G. H., and Brown, P. (2006). Reduction in subthalamic $8-35 \mathrm{~Hz}$ oscillatory activity correlates with clinical improvement in Parkinson's disease. Eur. J. Neurosci. 23, 1956-1960. doi: 10.1111/j.1460-9568. 2006.04717.x

Kühn, A. A., Tsui, A., Aziz, T., Ray, N., Brücke, C., Kupsch, A., et al. (2009). Pathological synchronisation in the subthalamic nucleus of patients with Parkinson's disease relates to both bradykinesia and rigidity. Exp. Neurol. 215, 380-387.

Kuriakose, R., Saha, U., Castillo, G., Udupa, K., Ni, Z., Gunraj, C., et al. (2010). The nature and time course of cortical activation following subthalamic stimulation in Parkinson's disease. Cereb. Cortex 20, 1926-1936. doi: 10.1093/cercor/ bhp269

Lafreniere-Roula, M., Kim, E., Hutchison, W. D., Lozano, A. M., Hodaie, M., and Dostrovsky, J. O. (2010). High-frequency microstimulation in human globus 
pallidus and substantia nigra. Exp. Brain Res. 205, 251-261. doi: 10.1007/ s00221-010-2362-8

Lewis, S. J., and Barker, R. A. (2009). A pathophysiological model of freezing of gait in Parkinson's disease. Parkinsonism Relat. Disord. 15, 333-338. doi: 10.1016/j.parkreldis.2008.08.006

Lewis, S. J., and Shine, J. M. (2016). The next step: a common neural mechanism for freezing of gait. Neuroscientist 22, 72-82. doi: 10.1177/107385841455 9101

Maris, E., and Oostenveld, R. (2007). Nonparametric statistical testing of EEG- and MEG-data. J. Neurosci. Methods 164, 177-190. doi: 10.1016/j.jneumeth.2007. 03.024

Marsden, J. F., Limousin-Dowsey, P., Ashby, P., Pollak, P., and Brown, P. (2001). Subthalamic nucleus, sensorimotor cortex and muscle interrelationships in Parkinson's disease. Brain 124(Pt 2), 378-388. doi: 10.1093/brain/124.2.378

Milosevic, L., Kalia, S. K., Hodaie, M., Lozano, A. M., Fasano, A., Popovic, M. R., et al. (2018). Neuronal inhibition and synaptic plasticity of basal ganglia neurons in Parkinson's disease. Brain 141, 177-190. doi: 10.1093/brain/awx296

Mima, T., and Hallett, M. (1999). Corticomuscular coherence: a review. J. Clin. Neurophysiol. 16, 501-511. doi: 10.1097/00004691-199911000-00002

Moore, S. T., MacDougall, H. G., and Ondo, W. G. (2008). Ambulatory monitoring of freezing of gait in Parkinson's disease. J. Neurosci. Methods 167, 340-348. doi: 10.1016/j.jneumeth.2007.08.023

Moreau, C., Defebvre, L., Destée, A., Bleuse, S., Clement, F., Blatt, J. L., et al. (2008). STN-DBS frequency effects on freezing of gait in advanced Parkinson disease. Neurology 71, 80-84.

Mori, S. (1987). Integration of posture and locomotion in acute decerebrate cats and in awake, freely moving cats. Prog. Neurobiol. 28, 161-195. doi: 10.1016/ 0301-0082(87)90010-4

Nieuwboer, A., Dom, R., De Weerdt, W., Desloovere, K., Janssens, L., and Stijn, V. (2004). Electromyographic profiles of gait prior to onset of freezing episodes in patients with Parkinson's disease. Brain 127(Pt 7), 1650-1660. doi: 10.1093/ brain/awh 189

Nonnekes, J., Snijders, A. H., Nutt, J. G., Deuschl, G., Giladi, N., and Bloem, B. R. (2015). Freezing of gait: a practical approach to management. Lancet Neurol. 14, 768-778. doi: 10.1016/S1474-4422(15)00041-1

Nutt, J. G., Bloem, B. R., Giladi, N., Hallett, M., Horak, F. B., and Nieuwboer, A (2011). Freezing of gait: moving forward on a mysterious clinical phenomenon. Lancet Neurol. 10, 734-744. doi: 10.1016/S1474-4422(11)70143-0

Pötter, M., Herzog, J., Siebner, H. R., Kopper, F., Steigerwald, F., Deuschl, G., et al. (2008). Subthalamic nucleus stimulation modulates audiospinal reactions in Parkinson disease. Neurology 70(Pt 2), 1445-1451. doi: 10.1212/01.wnl. 0000310422.49977.ea

Pötter-Nerger, M., and Volkmann, J. (2013). Deep brain stimulation for gait and postural symptoms in Parkinson's disease. Mov. Disord. 28, 1609-1615. doi: $10.1002 /$ mds. 25677

Pozzi, N. G., Canessa, A., Palmisano, C., Brumberg, J., Steigerwald, F., Reich, M. M., et al. (2019). Freezing of gait in Parkinson's disease reflects a sudden derangement of locomotor network dynamics. Brain 142, 2037-2050. doi: 10. 1093/brain/awz141

Rahman, S., Griffin, H. J., Quinn, N. P., and Jahanshahi, M. (2008). The factors that induce or overcome freezing of gait in Parkinson's disease. Behav. Neurol. 19, 127-136. doi: 10.1155/2008/456298

Salenius, S., Avikainen, S., Kaakkola, S., Hari, R., and Brown, P. (2002). Defective cortical drive to muscle in Parkinson's disease and its improvement with levodopa. Brain 125(Pt 3), 491-500. doi: 10.1093/brain/awf042

Schlenstedt, C., Shalash, A., Muthuraman, M., Falk, D., Witt, K., and Deuschl, G. (2017). Effect of high-frequency subthalamic neurostimulation on gait and freezing of gait in Parkinson's disease: a systematic review and meta-analysis. Eur. J. Neurol. 24, 18-26. doi: 10.1111/ene.13167

Schoffelen, J. M., Oostenveld, R., and Fries, P. (2005). Neuronal coherence as a mechanism of effective corticospinal interaction. Science 308, 111-113.

Scholten, M., Govindan, R. B., Braun, C., Bloem, B. R., Plewnia, C., Krüger, R., et al. (2016a). Cortical correlates of susceptibility to upper limb freezing in Parkinson's disease. Clin. Neurophysiol. 127, 2386-2393. doi: 10.1016/j.clinph. 2016.01.028

Scholten, M., Klotz, R., Plewnia, C., Wächter, T., Mielke, C., Bloem, B. R., et al. (2016b). Neuromuscular correlates of subthalamic stimulation and upper limb freezing in Parkinson's disease. Clin. Neurophysiol. 127, 610-620. doi: 10.1016/ j.clinph.2015.02.012

Scholten, M., Klemt, J., Heilbronn, M., Plewnia, C., Bloem, B. R., Bunjes, F., et al. (2017). Effects of subthalamic and nigral stimulation on Gait Kinematics in Parkinson's disease. Front. Neurol. 8:543. doi: 10.3389/fneur.2017.00543

Scholten, M., Schoellmann, A., Ramos-Murguialday, A., ópez-Larraz, E. L., Gharabaghi, A., and Weiss, D. (2020). Transitions between repetitive tapping and upper limb freezing show impaired movement-related beta band modulation. Clin. Neurophysiol. 131, 2499-2507. doi: 10.1016/j.clinph.2020. 05.037

Seuthe, J., Kuball, K., Hoffmann, A. K., Weisser, B., Deuschl, G., and Schlenstedt, C. (2021). Validation of the German version of the new freezing of gait questionnaire for people with Parkinson's disease. Parkinsons Dis. 2021:8841679. doi: 10.1155/2021/8841679

Shine, J. M., Naismith, S. L., and Lewis, S. J. (2013). The differential yet concurrent contributions of motor, cognitive and affective disturbance to freezing of gait in Parkinson's disease. Clin. Neurol. Neurosurg. 115, 542-545. doi: 10.1016/j. clineuro.2012.06.027

Singh, A., Plate, A., Kammermeier, S., Mehrkens, J. H., Ilmberger, J., and Botzel, K. (2013). Freezing of gait-related oscillatory activity in the human subthalamic nucleus. Basal Ganglia 3, 25-32.

Snijders, A. H., Haaxma, C. A., Hagen, Y. J., Munneke, M., and Bloem, B. R. (2012). Freezer or non-freezer: clinical assessment of freezing of gait. Parkinsonism Relat. Disord. 18, 149-154. doi: 10.1016/j.parkreldis.2011.09.006

Snijders, A. H., Takakusaki, K., Debu, B., Lozano, A. M., Krishna, V., Fasano, A., et al. (2016). Physiology of freezing of gait. Ann. Neurol. 80, 644-659. doi: $10.1002 /$ ana. 24778

Storzer, L., Butz, M., Hirschmann, J., Abbasi, O., Gratkowski, M., Saupe, D., et al. (2017). Bicycling suppresses abnormal beta synchrony in the Parkinsonian basal ganglia. Ann. Neurol. 82, 592-601. doi: 10.1002/ana.25047

Sutton, A. C., Yu, W., Calos, M. E., Smith, A. B., Ramirez-Zamora, A., Molho, E. S., et al. (2013). Deep brain stimulation of the substantia nigra pars reticulata improves forelimb akinesia in the hemiparkinsonian rat. J. Neurophysiol. 109, 363-374. doi: 10.1152/jn.00311.2012

Takakusaki, K. (2013). Neurophysiology of gait: from the spinal cord to the frontal lobe. Mov. Disord. 28, 1483-1491. doi: 10.1002/mds.25669

Thevathasan, W., Pogosyan, A., Hyam, J. A., Jenkinson, N., Foltynie, T., Limousin, P., et al. (2012). Alpha oscillations in the pedunculopontine nucleus correlate with gait performance in parkinsonism. Brain 135(Pt 1), 148-160. doi: 10.1093/ brain/awr315

Tinkhauser, G., Pogosyan, A., Tan, H., Herz, D. M., Kühn, A. A., and Brown, P. (2017). Beta burst dynamics in Parkinson's disease OFF and ON dopaminergic medication. Brain 140, 2968-2981. doi: 10.1093/brain/awx252

Toledo, J. B., López-Azcárate, J., Garcia-Garcia, D., Guridi, J., Valencia, M., Artieda, J., et al. (2014). High beta activity in the subthalamic nucleus and freezing of gait in Parkinson's disease. Neurobiol. Dis. 64, 60-65. doi: 10.1016/j.nbd.2013. 12.005

Udupa, K., Bahl, N., Ni, Z., Gunraj, C., Mazzella, F., Moro, E., et al. (2016). Cortical plasticity induction by pairing subthalamic nucleus deep-brain stimulation and primary motor cortical transcranial magnetic stimulation in Parkinson's disease. J. Neurosci. 36, 396-404. doi: 10.1523/JNEUROSCI.2499-15. 2016

Valldeoriola, F., Muñoz, E., Rumia, J., Roldán, P., Cámara, A., Compta, Y., et al. (2019). Simultaneous low-frequency deep brain stimulation of the substantia nigra pars reticulata and high-frequency stimulation of the subthalamic nucleus to treat levodopa unresponsive freezing of gait in Parkinson's disease: a pilot study. Parkinsonism Relat. Disord. 60, 153-157.

Vercruysse, S., Spildooren, J., Heremans, E., Vandenbossche, J., Levin, O., Wenderoth, N., et al. (2012). Freezing in Parkinson's disease: a spatiotemporal motor disorder beyond gait. Mov. Disord. 27, 254-263. doi: 10.1002/mds.24015

Weiss, D., Breit, S., Hoppe, J., Hauser, A. K., Freudenstein, D., Krüger, R., et al (2012). Subthalamic nucleus stimulation restores the efferent cortical drive to muscle in parallel to functional motor improvement. Eur. J. Neurosci. 35, 896-908. doi: 10.1111/j.1460-9568.2012.08014.x

Weiss, D., Klotz, R., Govindan, R. B., Scholten, M., Naros, G., Ramos-Murguialday, A., et al. (2015). Subthalamic stimulation modulates cortical motor network activity and synchronization in Parkinson's disease. Brain 138(Pt 3), 679-693. doi: 10.1093/brain/awu380 
Weiss, D., Milosevic, L., and Gharabaghi, A. (2019). Deep brain stimulation of the substantia nigra for freezing of gait in Parkinson's disease: is it about stimulation frequency? Parkinsonism Relat. Disord. 63, 229-230.

Weiss, D., Schoellmann, A., Fox, M. D., Bohnen, N. I., Factor, S. A., Nieuwboer, A., et al. (2020). Freezing of gait: understanding the complexity of an enigmatic phenomenon. Brain 143, 14-30. doi: 10.1093/brain/awz314

Weiss, D., Walach, M., Meisner, C., Fritz, M., Scholten, M., Breit, S., et al. (2013). Nigral stimulation for resistant axial motor impairment in Parkinson's disease? A randomized controlled trial. Brain 136(Pt 7), 2098-2108. doi: 10.1093/brain/ awt 122

Wichmann, T., Kliem, M. A., and DeLong, M. R. (2001). Antiparkinsonian and behavioral effects of inactivation of the substantia nigra pars reticulata in hemiparkinsonian primates. Exp. Neurol. 167, 410-424. doi: 10.1006/exnr.2000. 7572

Conflict of Interest: DW received honoraria and/or research support from Abbot, Abbvie, Bial, Boston Scientific, Kyowa Kirin, Medtronic, and Stada pharma.
The remaining authors declare that the research was conducted in the absence of any commercial or financial relationships that could be construed as a potential conflict of interest.

Publisher's Note: All claims expressed in this article are solely those of the authors and do not necessarily represent those of their affiliated organizations, or those of the publisher, the editors and the reviewers. Any product that may be evaluated in this article, or claim that may be made by its manufacturer, is not guaranteed or endorsed by the publisher.

Copyright (c) 2022 Breu, Schneider, Klemt, Cebi, Gharabaghi and Weiss. This is an open-access article distributed under the terms of the Creative Commons Attribution License (CC BY). The use, distribution or reproduction in other forums is permitted, provided the original author(s) and the copyright owner(s) are credited and that the original publication in this journal is cited, in accordance with accepted academic practice. No use, distribution or reproduction is permitted which does not comply with these terms. 